\title{
IMPLEMENTASI SQUID PROXY PADA MIKROTIK DAN MONITORING TRAFFIC JARINGAN BERBASIS WEBSITE
}

\author{
Heru Kurniawan, Josep Dedy Irawan, FX. Ariwibisono \\ Program Studi Teknik Informatika S1, Fakultas Teknologi Industri \\ Institut Teknologi Nasional Malang, Jalan Raya Karanglo km 2 Malang, Indonesia \\ herukurniwan1928@gmail.com
}

\begin{abstract}
ABSTRAK
Semakin meningkatnya perilaku pengguna internet agar dapat mengakses konten-konten yang diinginkan, menjadikan administrator perlu untuk menjaga kestabilan dan kecepatan dalam akses internet. Meningkatnya jumlah pengguna tidak diimbangi dengan penambahan bandwidth internet.

Berdasarkan permasalahan yang ada, penelitian ini adalah melakukan implementasi proxy server menggunakan squid proxy yang terintegrasi dengan mikrotik pada sistem operasi ubuntu 11.10, serta monitoring traffic jaringan berbasis website menggunakan bahasa pemrograman php dan mysql sebagai database.

Dari hasil pengujian yang telah dilakukan, system dapat berfungsi $100 \%$, dengan dapat digunakannya pemblokiran situs dengan watu yang ditentukan, serta halaman monitoring dapat berjalan sesuai dengan kebutuhan sistem.
\end{abstract}

Kata Kunci : squid, proxy, php, web, monitoring, ubuntu.

\section{PENDAHULUAN}

Perkembangan teknologi pada masa sekarang ini begitu pesat sehingga memungkinkan pengguna untuk menghubungkan komputer melalui jaringan. Jaringan komputer cukup berkembang di Indonesia karena internet sudah mulai menjadi bagian hidup untuk kalangan menengah. Namun terdapat beberapa materi yang seharusnya tidak dikonsumsi oleh semua kalangan dan tidak cocok dengan budaya pengguna, seperti pornografi, judi dan beberapa hal yang bersifat kekerasan, dimana peraturan itu sudah tertulis di UUD RI No. 11 tahun 2008, tentang informasi dan transaksi elektronik khususnya di BAB II asas dan TUJUAN pada Pasal 3 tentang pemanfaatan teknologi informasi dan transaksi elektronik berdasarkan asas kepastian hukum, manfaat kehatihatian, iktikad baik dan kebebasan memilih teknologi.

Semakin meningkatnya perilaku pengguna internet agar dapat mengakses konten-konten yang diinginkan, menjadikan administrator perlu untuk menjaga kestabilan dan kecepatan dalam akses internet. Meningkatnya jumlah pengguna tidak diimbangi dengan penambahan bandwidth internet. Hal tersebut dikarenakan faktor biaya yang menjadi pertimbangan. Jumlah pengguna internet yang semakin banyak jika tidak diimbangi dengan penambahan bandwith dapat memunculkan permasalahan bagi para pengguna. Permasalahan tersebut terkait dengan kecepatan akses internet yang dirasa lama oleh para pengguna.

Kemukakan solusi yang anda buat untuk mengatasi permasalahan yang anda kemukakan, aplikasi dan metode yang anda buat untuk menyelesaikan permasalahan, keuntungan keuntungan apabila menggunakan aplikasi dan metode yang anda buat.
Berdasarkan permasalahan yang ada, impelentasi squid proxy server dapat memberikan manfaat berupa penghematan bandwidth, meningkatkan kinerja, mengatur lalu lintas web, browsing yang cepat dari sisi end user. Secara umum cara kerja squid proxy server ketika user melakukan akses konten pada halaman website secara berulangulang akan tersimpan dalam caching sehingga dapat mempercepat akses internet untuk membuka halaman website. Sehingga keharusan untuk menambah bandwidth yang lebih besar dengan biaya yang lebih mahal mampu diminimalisir.

\subsection{Rumusan Masalah}

1 Bagaimana Konfigurasi Proxy Server Terintegrasi Mikrotik Menggunakan Squid Proxy Pada Sistem Operasi Linux Ubuntu 11.10 ?

2 Bagaimana Membuat Sistem Monitoring Traffic Jaringan Berbasis Web?

\subsection{Tujuan}

1 Membangun Squid Proxy Pada Sistem Operasi Linux Ubuntu 11.10 Yang Terintegrasi Dengan Mikrotik Untuk Mengelola Jaringan Server.

2 Menghasilkan Sistem Monitoring Traffic Jaringan Berbasis WEB Menggunakan Bahasa Pemrograman PHP dan Mysql Sebagai Database.

\subsection{Batasan Masalah}

1 Konfigurasi Hanya Menggunakan Sistem Operasi Ubuntu 11.10 Lts Dan Mikrotik Rb750r2

2 Monitoring Traffic Jaringan Berbasis Website Hanya Menggunakan Bahasa Pemrograman 
Php.

\section{TINJAUAN PUSTAKA}

\subsection{Penelitian Terdahulu}

Pemanfaatan teknologi internet saat ini telah dimanfaatkan oleh seluruh kalangan masyarakat tidak memandang usia dan jenis pekerjaan. Survey APJII menunjukkan bahwa mayoritas pengguna internet berada dalam rentang umur 25-34 tahun sbesar 75,8\% dan untuk rentang umur 34-44 tahun sebesar 54,7\%. Peminat internet juga menjangkau berbagai profesi masyarakat yang ada hal ini dibuktikan oleh data survey APJII tahun 2016 menunjukkan pengguna di kalangan mahasiswa mencapai $89,7 \%$ sementara di kalangan pekerja mencapai $58,4 \%$. Dan perilaku pengguna internet menunjukkan $97,4 \%$ masyarakat menggunakan internet untuk mengakses media sosial, 96,4\% masyarakat melakukan akses konten berita dan 93,8\% akses konten pendidikan. Semakin meningkatnya perilaku pengguna internet agar dapat mengakses konten-konten yang diinginkan, menjadikan suatu instansi perlu untuk menjaga kestabilan dan kecepatan dalam akses internet. Terkadang meningkatnya jumlah pengguna di beberapa instansi tidak diimbangi dengan penambahan bandwidth internet. Hal tersebut dikarenakan faktor biaya yang menjadi pertimbangan oleh instansi yang bersangkutan. Jumlah pengguna internet yang semakin banyak jika tidak diimbangi dengan penambahan bandwidth dapat memunculkan permaslahan bagi para pengguna. Permasalah tersebut terkait dengan kecepatan akses internet yang dirasa lama oleh para pengguna. Implementasi squid proxy server dapat memberikan manfaat berupa penghematan bandwidth, meningkatkan kinerja, mengatur lalu lintas web, browsing yang cepat dari sisi end user. Secara umum cara kerja squid proxy server ketika user melakukan akses konten pada halaman website secara berulang-ulang akan tersimpan dalam caching sehingga dapat mempercepat akses internet untuk membuka halaman website. Penulisan ini bertujuan untuk melakukan analisa terhadap hasil implementasi squid proxy server dari segi kecepatan pengguna ketika melakukan akses internet. Hasil analisa menunjukkan bahwa terdapat selisih waktu anatra sebelum dan setelah implementasi proxy server mencapai 35.962 detik, waktu tersebut menunjukkan bahwa hasil implementasi proxy server mampu meningkatkan kecepatan akses internet bagi pengguna. [1].

Manajemen bandwith merupakan cara untuk mengatur jaringan komputer agar bandwith digunakan secara optimal dan terbagi merata ke semua pengguna internet. Bandwith merupakan perhitungan konsumsi transfer data telekomunikasi yang dihitung dalam satuan bit per detik (bps) yang terjadi antara komputer server dengan komputer client. Manajemen bandwith menggunakan metode PCQ-Queue Tree dan menerapkan monitoring software Cacti yang di konfigurasi di perangkat
Raspberry Pi. Hasil implementasi metode PCQ menggunakan Queue Tree mendapatkan peningkatan nilai QoS dilihat dari pengujian parameter : a) Throughput meningkat pada 1 komputer yang aktif sebesar $0,6 \%$, b) memperkecil delay sampai dengan 30 milisecond, c) Jitter paling besar nilai pada angka 0,69 millisecond. Selain meningkatkan nilai QoS, bandwidth Warnet SweetNet dapat dimonitoring menggunakan software Cacti. [2]

Monitoring jaringan merupakan suatu proses yang rutin dalam mengumpulkan data pada suatu jaringan dengan melakukan pemantauan pada setiap perubahan-perubahan yang terjadi dalam mempertahankan manajemen jaringan yang ada. Dalam perkembangan ilmu jaringan komputer yang semakin pesat dan merambak ke dalam lingkungan masyarakat, pengguna jaringan yang selalu menginginkan jaringannya aman dan efesien dengan tingkatan keamanan yang terjamin. Dengan peningkatan ukuran dan jumlah suatu perangkat jaringan maka akan semakin beresiko terjadinya gangguan jaringan. Cacti merupakan solusi pembuatan grafik atas sebuah jaringan yang lengkap dimana cacti dirancang untuk memanfaatkan kekuatan RRDTool atas penyimpanan data menggunakan tampilan kedalam bentuk grafik. Sifatnya yang intuitif dan mudah digunakan, sangat handal untuk instalasi LAN berukuran kecil hingga jaringan kompleks dengan ratusan device. Kegiatan monitoring jaringan merupakan salah satu kegiatan yang dilakukan dalam mengolah sistem jaringan di area tertentu dengan topologi tertentu. Berkaitan dengan monitoring sangat membutuhkan suatu teknologi monitoring agar dalam sistem networking dapat dipantau secara maksimal. [3]

Administrator jaringan, baik yang bekerja di perusahaan, warnet dan di kampus sering dibuat pusing dan berpikir tentang bagaimana solusi agar loading situs yang diakses oleh user atau pengguna dapat lebih cepat, pemblokiran situs-situs porno atau situs - situs yang sering membawa masalah dapat dilakukan dengan mudah, melakukan redirect akses atau hal lainnya yang bisa dilakukan melalui jaringan komputer juga dapat dilakukan dengan lebih mudahnya. Pemanfaatan jalur komunikasi dalam jaringan secara maksimal adalah faktor utama yang harus diperhatikan begitu juga dengan pengelolaannya baik itu hak akses pengguna maupun waktu akses yang disediakan. Masalah keamanan dan kenyamanan juga faktor yang perlu dipertimbangkan. Squid adalah salah satu software proxy terbaik yang biasa digunakan sebagai mesin caching proxy untuk klien-klien Web, seperti HTTP, HTTPS, FTP, gopher dan layanan sejenis lainnya, dengan squid juga mampu menurunkan konsumsi bandwidth sekaligus mempercepat waktu respons (respons time) karena halaman web yang pernah dikunjungi tidak perlu dipanggil ulang kembali semua telah tersimpan di dalam caching proxy yang mengakibatkan waktu akses menjadi lebih cepat. Squid memiliki setumpuk 
kendali akses yang dapat mendongkrak kecepatans server dan mampu menangani request melalui proses I/O tunggal. Squid bekerja menyimpan meta data, terutama pada objek yang sering diakses, mereka dijaga (di-cache) dalam memori RAM yang mampu melayani lookup pada DNS. Object caching tidak lain salah satu jalan untuk menyimpan/ mengoleksi objek internet, semisal data HTTP, HTTPS, FTP, gopher, dalam sebuah sistem lokal, sehingga akan lebih mudah dan lebih dekat bagi pengguna untuk mengambil objek dari pada harus mengambil objek dari sumbernya [4]

Monitoring adalah pemantauan yang dapat dijelaskan sebagai kesadaran tentang apa yang ingin diketahui, pemantauan berkadar tingkat tinggi dilakukan agar dapat membuat pengukuran melalui waktu pergerakan ke arah tujuan atau menjauh dari itu. Monitoring akan memberikan informasi tentang status dan kecenderungan bahwa pengukuran dan evaluasi yansg diselesaikan berulang dari waktu ke waktu, pemantauan umumnya dilakukan untuk tujuan tertentu, untuk memeriksa terhadap proses. QOS (Quality of services) atau lebih dikenal dengan Bandwidth Manajemen, merupakan metode yang digunakan untuk memenuhi kebutuhan tersebut.

Pada RouterOS Mikrotik penerapan QoS bisa dilakukan dengan fungsi Queue. Cara paling mudah untuk melakukan queue pada RouterOS adalah dengan menggunakan Simple Queue. Kita bisa melakukan pengaturan bandwidth secara sederhana berdasarkan IP Address client dengan menentukan kecepatan upload dan download maksimum yang bisa dicapai oleh client. Dari hasil pengujian sistem ini diketahui bahwa sistem dapat memberikan serangkaian informasi yang di butuhkan oleh seorang admin. Penampilan data berupa grafik memudahkan seorang admin untuk memantau sebuah jaringan. Pemanggilan logger dari mikrotik menggunakan perintah sesuai kebutuhan, koneksi antara mikrotik dengan web menggunaakan api php yang dapat disuaikan dengan kebutuhan. Sistem dapat diakses dengan menggunakan dekstop. [14]

\subsection{Jaringan Komputer}

Jaringan komputer adalah dua atau lebih komputer yang terhubung satu sama lain dan digunakan untuk berbagi data. Jaringan komputer dibangun dengan kombinasi hardware dan software.

Untuk membuat jaringan komputer, switch dan router menggunakan berbagai protokol dan algoritma untuk bertukar informasi dan untuk membawa data ke titik akhir yang diinginkan. Setiap titik akhir (kadang disebut host) dalam jaringan memiliki pengenal unik, sering kali alamat IP atau alamat Media Access Control yang digunakan untuk menunjukkan sumber atau tujuan transmisi. Endpoint dapat mencakup server, komputer pribadi, telepon, dan berbagai jenis hardware jaringan.

Jaringan komputer merupakan jaringan yang menggunakan gabungan teknologi kabel dan wireless.
Perangkat jaringan berkomunikasi melalui medium transmisi kabel atau wireless. Untuk jaringan yang menggunakan kabel, Anda mungkin membutuhkan optical fiber, coaxial cable, atau kabel tembaga. Sementara itu, jalur jaringan wireless termasuk jaringan komputer yang menggunakan koneksi data wireless untuk menghubungkan titik akhir. Titik akhir ini termasuk radio siaran, radio seluler, microwave, dan satelit.

Jaringan bisa menjadi private atau publik. Jaringan private biasanya memerlukan user untuk memasukkan kredensial untuk mengakses jaringan. Biasanya, ini diberikan secara manual oleh administrator jaringan atau diperoleh langsung oleh pengguna melalui kata sandi atau dengan kredensial lainnya. Jaringan publik seperti internet tidak membatasi akses. [5]

\subsection{Proxy Server}

Proxy merupakan sistem yang memungkinkan pengguna untuk bisa mengakses jaringan internet memakai IP address berbeda yang diterima perangkat. Sistem seperti ini memanfaatkan proxy server supaya bisa bekerja dengan baik. Proxy untuk server sendiri adalah perangkat atau komputer yang dipakai untuk menyediakan berbagai layanan proxy yang diperlukan pengguna.

Dengan begitu, user tetap bisa menggunakan jaringan internet yang dipakai sekarang dan menghubungkannya ke proxy tersebut. Ada banyak proxy yang disediakan di internet, sesuaikan saja dengan kebutuhan dan keinginan pengguna masingmasing. Bahkan tidak sedikit dari proxy tersebut yang non berbayar alias gratis.

Sangat mudah untuk menemukan penyedia proxy, seperti halnya penjual buku, sepatu, baju hingga penyedia tas. Hanya saja Anda harus memahami fungsi dan juga cara kerja proxy sebelum memakainya. Setelah tahu pengertian proxy, Anda harus paham kenapa proxy harus digunakan. Ada banyak alasan kenapa pengguna harus menggunakan proxy.

Contohnya akses internet yang telah diblokir sehingga tidak dapat membuka situs dari alamat ip atau negara lain. Dengan adanya proxy, informasi seputar diri Anda pribadi juga tidak akan bisa diketahui. Selain itu, dengan adanya proxy banyak sekolah bisa membatasi akses untuk website tertentu sehingga siswa tidak bisa mengakses website yang dilarang tersebut. Metode ini dikenal dengan nama proxy web.[8]

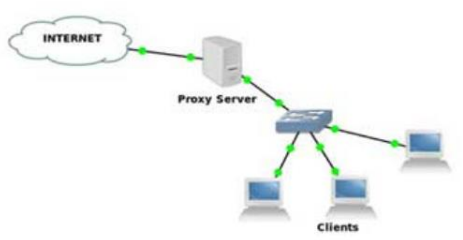

Gambar 1 Model Proxy Server 


\subsection{Squid Proxy}

Squid adalah sebuah program atau aplikasi gratis (free software) dengan lisensi GPL (GNU General Public License) yang dirancang untuk melakukan fungsi sebagai web proxy dan web caching. Squid juga melakukan fungsi DNS caching.

Sebagai web proxy maksudnya adalah squid akan menjadi perantara antara klien web dan web server dalam transaksi web. Squid akan memforward request klien ke server. Sedangkan sebagai web cache, Squid akan berusaha menyimpan objek atau konten web yang direquest oleh klien ke dalam cache, jika objek atau konten dengan URL yang sama di request kembali, maka Squid akan memberikan objek yang sebelum sudah tersimpan didalam cache tanpa harus melakukan koneksi ke server.

Jika merujuk pada lisensi GPL, maka kita bisa mendapatkan source code Squid secara gratis, bebas menggunakannya untuk tujuan apapun, bebas dipelajari bahkan dimodifikasi, bebas digandakan dan disebarluaskan. [9]

\section{ANALISIS DAN PERANCANGAN}

\subsection{Analisis Sistem}

Sistem ini membutuhkan web interface untuk monitoring traffic jaringan user yang telah terhubung dengan proxy server.

\subsubsection{Analisis Kebutuhan Fungsional}

Kebutuhan fungsional dari sistem yang akan dibuat :

1. Sistem dapat ter-integrasi dengan mikrotik sebagai layanan penghubung antara user dan proxy server.

2. Ssistem dapat Monitoring user dengan logger pada squid proxy.

3. Sistem dapat Monitoring traffic jaringan lokal dengan logger dan grafik berbasis website

4. Sistem dapat memblokir situs serta waktu yang tidak boleh diakses oleh user sesuai dengan keinginan administrator.

\subsubsection{Analisis Kebutuhan Sistem}

Analisis diperuntukan untuku apa saja yang dibutuhkan dalam membanun sistem, seperti kebutuhan hardware dan software yang digunakan, berikut adalah kebutuhan sistem :

\section{A. Hardware}

Kebutuhan hardware untuk sistem :

1. PC Server

2. Router Mikrotik Tipe RB750r2

3. Kabel UTP

4. Device Client : Laptop

B. Software

Kebutuhan Software untuk Sistem :

1. Sistem Operasi Ubuntu ( Sebagai Serve )

2. Server Proxy Eksternal ( Squid Proxy )

3. Wireshark ( Menampung data traffic jaringan )

4. Winbox

\subsection{Gambaran Teknologi Yang Akan \\ Dikembangkan \\ Pada Gambar dibawah merupakan topologi} jaringan yang akan di gunakan dimana Internet sebagai uji coba untuk penggunaan proxy server setelah system sudah jadi. Kemudian di hubungkan dengan router mikrotik yang di gunakan untuk konfigurasi proxy server sebagai penghubung. dari router mikrotik di hubungkan menggunakan access point sebagai pemancar sinyal, kemudian terdapat 3 user yang di hubungkan ke hotspot yang telah di konfigurasi

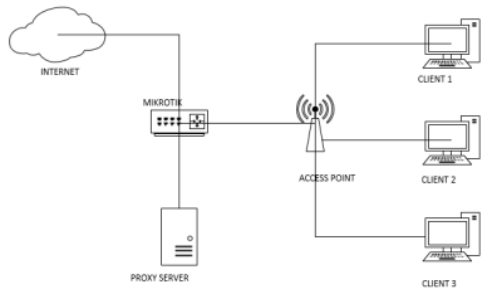

Gambar 2 Topologi Jaringan

\subsection{Blok Diagram Sistem}

Blok diagram merupakan diagram blok di atas merupakan alur dari sistem yang akan di gunakan administrator sesuai dengan konfigurasi proxy server dengan mikrotik, administrator dapat manajemen akses user terhadap jaringan sesuai waktu dan situs yang tidak boleh diakses oleh user.

1. User terhubung dengan jaringan mikrotik

2. User menggunakan jaringan sesuai dengan konfigurasi yang dibuat pada Proxy Server, dengan mendapatkan IP address dari mikrotik, kemudian konfigurasi proxy server 172.16.1.23 port 3128.

3. User request ke Proxy Server melalui Mikrotik sebelum terhubung ke jaringan internet.

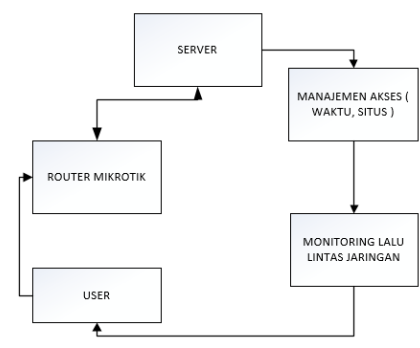

Gambar 3 Blok diagram sistem

\subsection{Flowchart Sistem}

Flowchart sistem ini menjelaskan proses berjalananya aplikasi seperti ditunjukkan pada Gambar 4. 


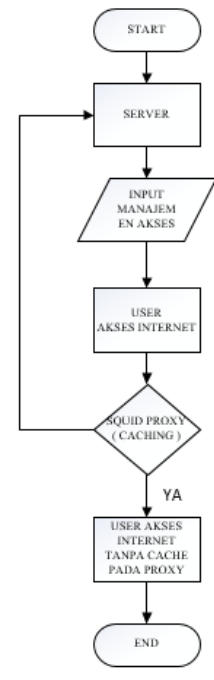

Gambar 4 Flowchart Sistem

Pada Gambar 4 merupakan Flowchart dari jalannya sistem terutama pada fitur konfigurasi proxy server dan manajemen akses situs serta waktu yang tidak diijinkan, yang di integrasikan dengan mikrotik, user yang menggunakan internet pada jaringan, jika terdapat data cache maka server akan memberikan data tersebut dengan cache halaman yang pernah diakses oleh client yang lain. jika tidak ada data maka server menyimpan data cache yang diakses oleh user pada internet.

\subsection{Desain Layout}

Dalam Pembuatan Sistem ini membutuhkan faktor pendukung yaitu pembuatan desain layout atau desain prototype interface website yang sedang di bangun.

\subsection{Interface Login}

Pada Gambar 5 merupakan halaman dari login admin untuk masuk dalam sistem moniroting jaringan.

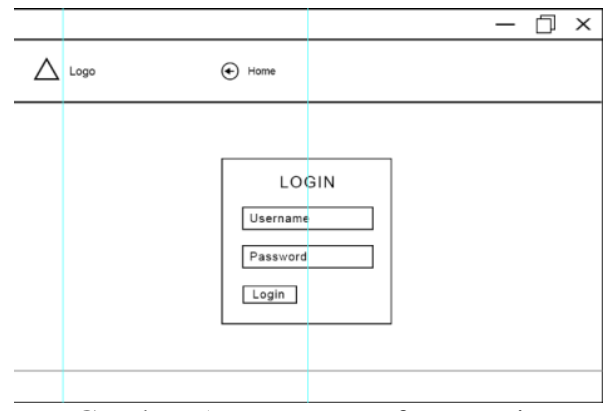

Gambar 5 Layout Interface Login

\subsection{Interface Dashboard}

Pada Gambar 6 merupakan halaman dashboard dimana logger dan statistik jaringan dengan grafik ditampilkan.

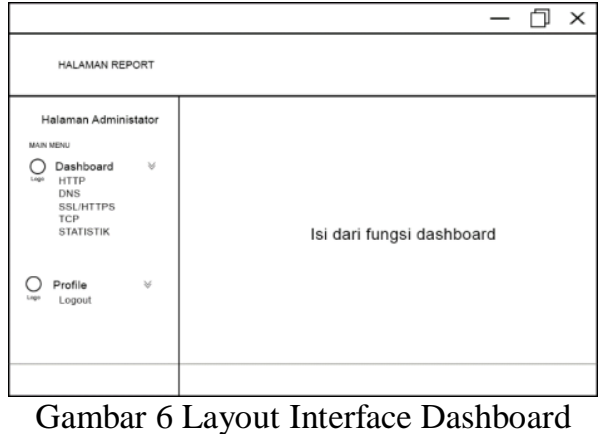

\subsection{Interface Log Jaringan}

Pada Gambar 7 merupakan desain interface untuk memonitoring logger jaringan, terdapat tabel hasil dari file csv yang telah di import.

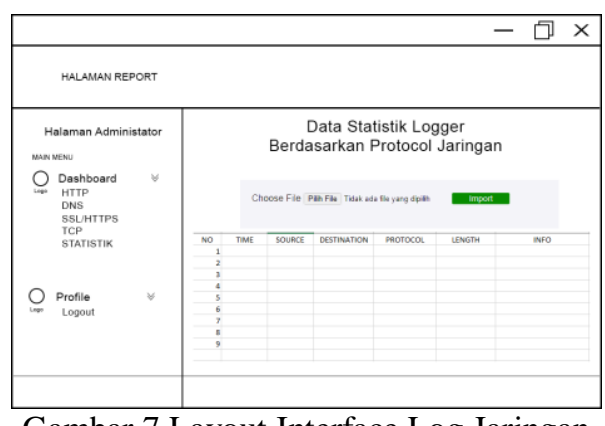

Gambar 7 Layout Interface Log Jaringan

\subsection{Interface Satistik Berdasarkan Protocol Jaringan}

Pada Gambar 8 merupakan desain interface untuk memonitoring statistik jaringan dengan grafik, terdapat grafik statistik berdasarkan protocol jaringan.

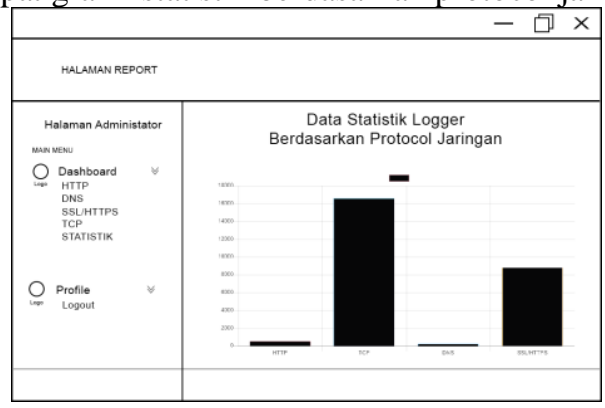

Gambar 8 Layout Interface Statistik

\section{IMPLEMENTASI DAN PENGUJIAN}

4.1. Implementasi Squid Proxy

Pada Gambar 9 Merupakan Konfigurasi Squid Proxy pada ubuntu. Konfigurasi ini agar Proxy pada server dapat berjalan dan digunakan oleh client yang terhubung dengan mikrotik. konfigurasi ini terdapat pada file /etc/squid/squid.conf. 


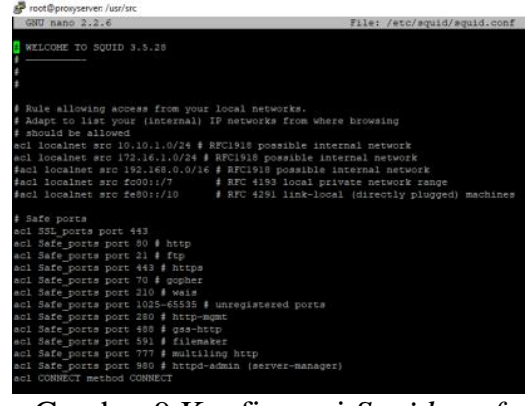

Gambar 9 Konfigurasi Squid.conf

Pada Gambar 4.19 Merupakan konfigurasi squid proxy untuk menentukan minimum, maxsimum, directory, serta jumlah folder yang akan dibuat untuk menyimpan data cache pada proxy squid, konfigurasi ini terdapat pada file /etc/squid/squid.conf

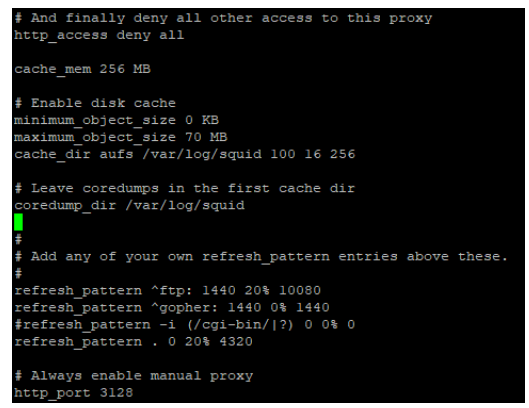

Gambar 10 Konfigurasi cache

Pada Gambar 11 Merupakan Konfigurasi Squid Proxy pada ubuntu. Konfigurasi ini dilakukan untuk manajemen akses jaringan yang digunakan oleh client sesuai dengan waktu dan situs yang sudah ditentukan. konfigurasi ini terdapat pada file /etc/squid/blokir.txt.

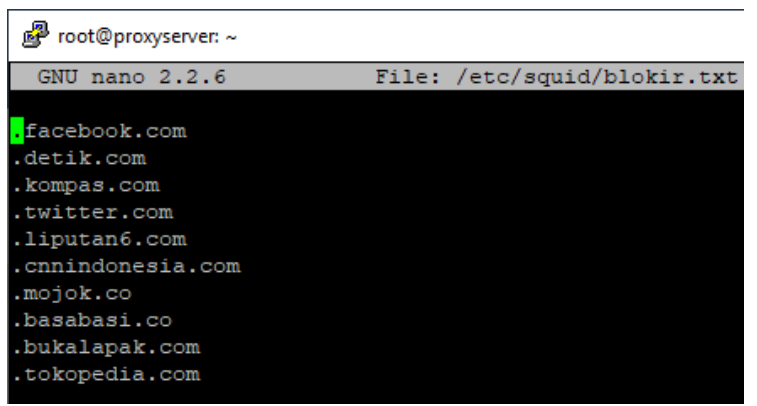

Gambar 11 Konfigurasi blokir.txt

Pada Gambar 4.12 Merupakan Konfigurasi Squid Proxy pada ubuntu. Konfigurasi ini agar konfigurasi pada file /etc/squid/blokir.txt pada proxy server dapat berjalan, sehingga dapat manajemen akses jaringan client sesuai waktu dan situs yang tidak boleh diakses pada konfigurasi ini terdapat pada file /etc/squid/squid.conf.

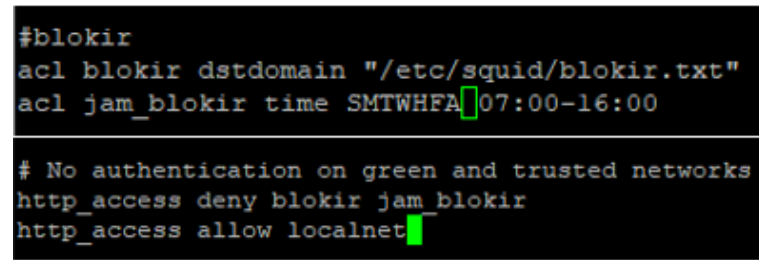

Gambar 12 Konfigurasi blokir.txt

\subsection{Pengujian Squid Proxy}

Pada Gambar 12 merupakan pengujian dari squid proxy berupa data yang digunakan oleh squid proxy sebagai penyimpanan file cache. Hasil didapatkan dengan perintah tail $-f$ /var/log/squid/cache.log | ccze.

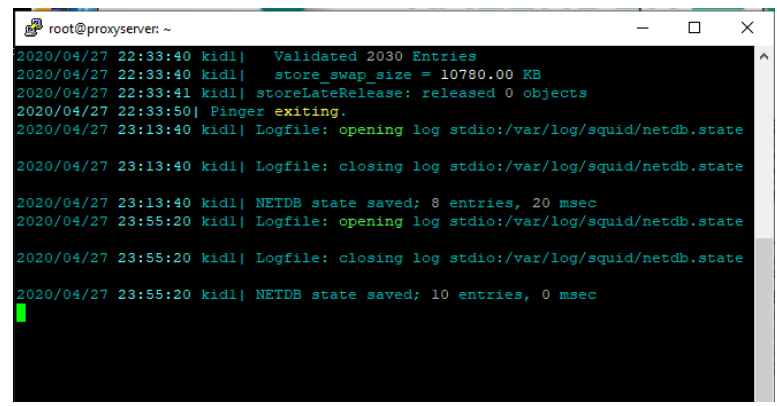

Gambar 13 Data Cache Squid Proxy

Pada Gambar 14 merupakan pengujian dari squid proxy berupa data log dari jaringan yang melewati squid itu sendiri. Hasil didapatkan dengan perintah tail $-f / v a r / l o g / s q u i d / a c c e s s . l o g \mid$ ccze.

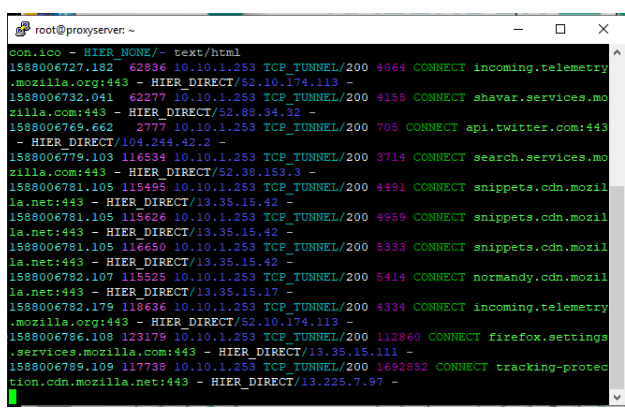

Gambar 14 Tampilan Log Squid Proxy

Pada Gambar 15 merupakan pengujian dari squid proxy berupa pemblokiran situs.dimana situs yang diblokir ialah www.facebook.com pada jam 07:00-16:00 dan didapatkan hasil bahwa akses ditolak dan situs tidak dapat dikunjungi.

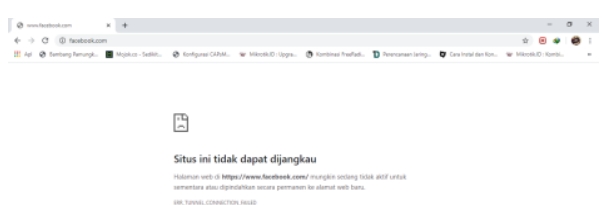

Gambar 15 Tampilan Blokir Situs 
Pada Tabel 1 Pengujian dari squid proxy, untuk melakukan blokir situs tertentu pada jam tertentu, pada pengujian ini menggunakan 10 situs, dari 10 situs yang diblokir dapat disimpulkan bahwa sistem berjalan dengan baik, sehingga terjadi pembatasan akses internet pada pengguna sesuai waktu yang ditertentukan.

Tabel 1 Pengujian Blokir situs sesuai dengan waktu

\begin{tabular}{|c|c|c|c|c|c|}
\hline \multirow{2}{*}{ No } & \multicolumn{2}{|c|}{ Blokir } & \multicolumn{2}{c|}{ Akses Internet } & \multirow{2}{*}{ Hasil } \\
\cline { 2 - 5 } & Situs (.com) & $\begin{array}{c}\text { Waktu } \\
\text { (SMTWHFA) }\end{array}$ & 07:00-16:00 & 16:01-06:59 & \\
\hline 1 & Facebook & $07: 00-16: 00$ & Tidak diijinkan & diijinkan & Berhasil \\
\hline 2 & Detik & $07: 00-16: 00$ & Tidak diijinkan & diijinkan & Berhasil \\
\hline 3 & Kompas & $07: 00-16: 00$ & Tidak diijinkan & diijinkan & Berhasil \\
\hline 4 & Twitter & $07: 00-16: 00$ & Tidak diijinkan & diijinkan & Berhasil \\
\hline 5 & Liputan6 & $07: 00-16: 00$ & Tidak diijinkan & diijinkan & Berhasil \\
\hline 6 & Cnnindonesia & $07: 00-16: 00$ & Tidak diijinkan & diijinkan & Berhasil \\
\hline 7 & Mojok & $07: 00-16: 00$ & Tidak diijinkan & diijinkan & Berhasil \\
\hline 8 & Basabasi & $07: 00-16: 00$ & Tidak diijinkan & diijinkan & Berhasil \\
\hline 9 & Bukalapak & $07: 00-16: 00$ & Tidak diijinkan & diijinkan & Berhasil \\
\hline 10 & Tokopedia & $07: 00-16: 00$ & Tidak diijinkan & diijinkan & Berhasil \\
\hline
\end{tabular}

\subsection{Pengujian Halaman Interface}

Pada Gambar 16 merupakan pengujian dari halaman interface login admin, dimana pada halaman tersebut terdapat form username dan password yang telah di buat pada database

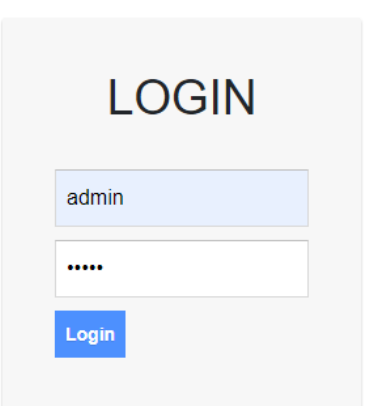

Gambar 16 Halaman Login Admin

Pada Gambar 17 merupakan pengujian dari halaman interface dashboard log protocol http. Dimana terdapat form import file yang berekstensi csv.serta tabel data logger dari database.

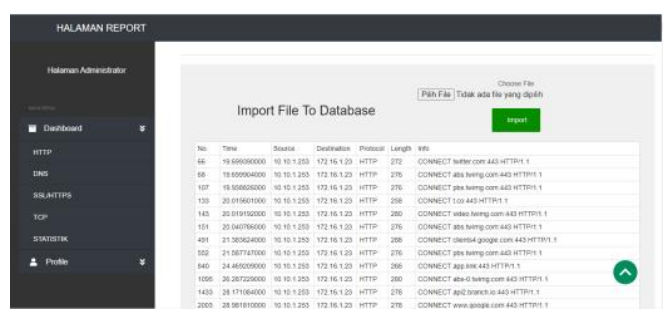

Gambar 17 Halaman Log HTTP

Pada Gambar 18 merupakan pengujian dari halaman interface dashboard statistik dari jaringan yang ditampilkan dengan grafik berdasarkan protocol jaringan yang di akses.

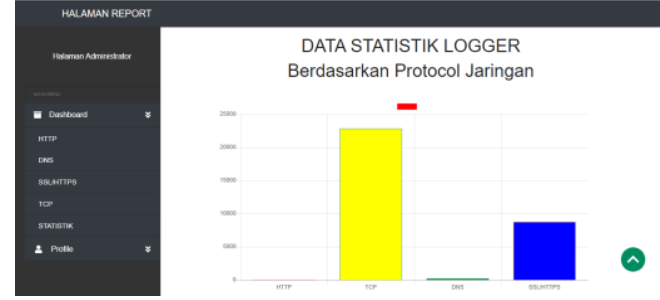

Gambar 18 Halaman Statistik Jaringan

Pada Tabel 2 Pengujian dari halaman interface, untuk melakukan memonitoring jaringan melalui file yang sudah di impoort, terdapat beberapa menu untuk menampilkan log dan juga statistik grafik sesuai dengan protocol yang diakses pada database.

Tabel 2 Pengujian Halaman Interface

\begin{tabular}{|c|l|c|c|}
\hline \multirow{2}{*}{ NO } & \multirow{2}{*}{ MENU } & \multicolumn{2}{|c|}{ HASIL } \\
\cline { 3 - 4 } & & Import File csv & Log/Grafik \\
\hline 1 & HTTP & Berhasil & Berhasil \\
\hline 2 & DNS & Berhasil & Berhasil \\
\hline 3 & SSL/HTTPS & Berhasil & Berhasil \\
\hline 4 & STATISTIK & Berhasil & Berhasil \\
\hline
\end{tabular}

\section{KESIMPULAN DAN SARAN}

\subsection{Kesimpulan}

Berdasarkan Hasil dari Rancang Bangun Sistem yang telah dilakukan maka didapat beberapa kesimpulan sebagai berikut:

1. Pengujian Squid Proxy dengan sistem operasi Linux Ubuntu 11.10 dapat berjalan $100 \%$

2. Pengujian blokir situs sesuai dengan waktu yang tidak diperbolehkan dapat berjalan.

3. Halaman Monitoring dapat berfungsi sesuai dengan kebutuhan sistem.

4. Dari pengujian sistem dapat berjalan dengan baik menggunakan bahasa pemrograman PHP dan MySQL sebagai database.

\subsection{Saran}

Adapun saran setelah melakukan pengujian, agar kedepannya sistem ini dapat dikembangkan yaitu sebagai berikut :

1. Sistem memiliki fitur transparent proxy untuk memudahkan administrator dalam mengelola client yang terhubung.

2. Sistem dapat melakukan pengelompokan terhadap client dalam pengelolaan situs dan waktu yang tidak boleh diakses.

3. Sistem dapat melakukan monitoring traffic secara langsung tanpa menampung data dari wireshark

\section{DAFTAR PUSTAKA}

[1] Khasana NF , 2017 . Performa Kecepatan Akses Internet Dengan Squid Proxy Server Pada Ubuntu Server 10.10. INFORMATICS FOR EDUCATORS AND PROFESSIONAL. 
[2] Nurfiana, Dani Ramanda, 2019. IMPLEMENTASI METODE PCQ-QUEUE TREE PADA ROUTER MIKROTIK DAN MONITORING CACTI UNTUK PENINGKATAN QUALITY OF SERVICE. Jurnal Ilmiah Teknologi Informasi dan Robotika(JIFTI).

[3] Daulay KN , 2019. MONITORING JARINGAN MENGGUNAKAN APLIKASI CACTI DI STMIK MURA LUBUKLINGGAU. JIK, VOL. $\mathrm{X}$

[4] Djumhadi ,2019. Manajemen Proxy Server dan Hak Akses Internet Menggunakan SQUID di Universitas Mulia . Program Studi Informatika, Fakultas Ilmu Komputer, Universitas Mulia (EISSN 2580-1503 | P-ISSN : 2442-9562)

[5] "Jaringan Komputer:Pengertian,Topologi, dan Jenis-Jenisnya". dewaweb.com. 6 November 2018. $27 \quad$ Maret 2020. https://www.dewaweb.com/blog/jaringankomputer-pengertian-topologi-dan-jenisjenisnya/

[6] "Mengenal Lebih Dekat Tentang Apa Itu Ubuntu". jetorbit.com. 10 Juli 2019. 27 Maret 2020. https://www.jetorbit.com/blog/mengenallebih-dekat-tentang-apa-itu-ubuntu/

[7] “Sejarah Mikrotik Lengkap: Pengertian, Jenis, Fitur, Fungsi Mikrotik.”. toriqa.com. 7 Februari 2020. 20 Juni 2020. https://toriqa.com/sejarahmikrotik/

[8] "Pengertian Proxy dan Jenis-Jenisnya" . qwords.com. 09 Januari 2020. 27 Maret 2020. https://qwords.com/blog/pengertian-proxy/
[9] "Mengenal SQUID | Panduan Praktis Squid “ dokter-squid.com. 07 Januari 2017. 27 Maret 2020. https://dokter-squid.com/mengenal-squid/

[10] "Kenali Pengertian Wireshark Beserta Fungsi dan Cara kerjanya, Lengkap! nesabamedia.com. 14 Desember 2019. 30 Mei 2020.

https://www.nesabamedia.com/pengertianwireshark/

[11] "Pengertian Dan Cara Kerja Firewall ". Dewaweb.com. 04 Juni 2019. 27 Maret 2020. https://www.dewaweb.com/blog/pengertianfirewall-dan-cara-kerjanya/

[12] "Pengertian Protocol Jaringan Serta Fungsi dan Jenisnya " Niagahoster.co.id. 24 Mei 2018. 06 Mei 2020. https://www.niagahoster.co.id/blog/protokolkomunikasi/

[13] “ Panduan phpMyAdmin Untuk Pemula “ dewaweb.com. 22 Februari 2018. 30 Mei 2020. https://www.dewaweb.com/blog/panduanphpmyadmin-untuk-pemula/

[14] Jayanto DR, 2019. Rancang Bangun Sistem Monitoring Jaringan Menggunakan Mikrotik Router OS.JATI ( Jurnal Mahasiswa Teknik Informatika ) Vol.3 No.1, Maret 2019

[15] " Berkenalan dengan ubuntu " dewaweb.com. 28 November 2018. 20 Juni 2020. https://www.dewaweb.com/blog/berkenalandengan-ubuntu/ 